\title{
openheart CT coronary angiography and COVID-19: inpatient use in acute chest pain service
}

\author{
Michael Cronin (D) , ${ }^{1}$ Peter Wheen, ${ }^{2}$ Richard Armstrong, ${ }^{2}$ Rajesh Kumar (D) , ${ }^{2}$ \\ Alannah McMahon, ${ }^{3}$ Max White, ${ }^{3}$ Niall Sheehy, ${ }^{4}$ Geraldine McMahon, ${ }^{5}$ \\ Ross T Murphy, ${ }^{2}$ Caroline Daly ${ }^{2}$
}

To cite: Cronin M, Wheen $P$, Armstrong R, et al. CT coronary angiography and COVID-19: inpatient use in acute chest pain service. Open Heart 2021;8:e001548. doi:10.1136/ openhrt-2020-001548

Received 8 December 2020 Revised 3 February 2021 Accepted 5 March 2021
A) Check for updates

\section{(C) Author(s) (or their} employer(s)) 2021. Re-use permitted under CC BY-NC. No commercial re-use. See rights and permissions. Published by BMJ.

${ }^{1}$ Saint James's Hospital, Dublin, Ireland

${ }^{2}$ Cardiology, Saint James's Hospital, Dublin, Ireland ${ }^{3}$ Medicine, Trinity College Dublin, Dublin, Ireland

${ }^{4}$ Radiology, Saint James's Hospital, Dublin, Ireland ${ }^{5}$ Emergency Medicine, Saint James's Hospital, Dublin, Ireland

Correspondence to

Dr Michael Cronin;

michaelcronin@rcsi.ie

\section{ABSTRACT}

Objectives CT coronary angiography (CTCA) is a wellvalidated clinical tool in the evaluation of chest pain. In our institution, CTCA availability was increased in January 2020, and subsequently, expanded further to replace all exercise testing during the COVID-19 pandemic. Our objective was to assess the impact of increased utilisation of CTCA on length of stay in patients presenting with chest pain in the prepandemic era and during the COVID-19 pandemic.

Methods Study design was retrospective. Patients referred for cardiology review between October 2019 and May 2020 with chest pain and/or dyspnoea were broken into three cohorts: a baseline cohort, a cohort with increased CTCA availability and a cohort with increased CTCA availability, but after the national lockdown due to COVID-19. Coronary angiography and revascularisation, length of stay and 30-day adverse outcomes were assessed.

Results 513 patients ( $35.3 \%$ female) presented over cohorts 1 ( $n=179), 2(n=182)$, and $3(n=153)$. CTCA use increased from $7.8 \%$ overall in cohort $1 \%$ to $20.4 \%$ in cohort 3. Overall length of stay for the patients undergoing CTCA decreased from a median of 4.2 days in cohort 1 to 2.5 days in cohort 3 , with no increase in 30 days adverse outcomes. Invasive coronary angiogram rates were $45.8 \%$, $39 \%$ and $34.2 \%$ across the cohorts. $29.6 \%$ underwent revascularisation in cohort $1,15.9 \%$ in cohort 2 and to $16.4 \%$ in cohort 3.

Conclusions Increased CTCA availability was associated with a significantly reduced length of stay both preCOVID-19 and post-COVID-19 lockdown, without any increase in 30-day adverse outcomes.

\section{INTRODUCTION}

Chest pain accounts for up to $4 \%$ of all attendances at the emergency department (ED). ${ }^{1}$ The prevalence of acute myocardial infarction in the undifferentiated ED patient with a chief complaint of chest pain in the UK has been reported as $4 \% .^{2}$ CT coronary angiography (CTCA) has a clear role in low to intermediate chest pain presentations thought to be of cardiac origin. ${ }^{3}$ St. James Hospital is a tertiary referral centre for cardiology and

\section{Key questions}

What is already known about this subject?

- CT coronary angiography (CTCA) has been established in international guidelines as the first-line assessment for intermediate-risk chest pain thought to be of cardiac origin.

What does this study add?

- This study is designed to investigate the relationship between increased access to CTCA and length of hospital stay.

How might this impact on clinical practice?

- We envisage our findings to be referenced when encouraging the development of CTCA use within national healthcare systems, particularly in light of the increasing trend towards shortening length of hospital admissions within the context of an international pandemic.

provides primary percutaneous coronary intervention for over 500 patients per annum.

The UK in conjunction with National Institute for Health and Care Excellence (NICE) have proposed CTCA as the investigation of choice for the majority of patients presenting with new onset chest pain of suspected cardiac origin. ${ }^{4}$ CTCA is a non-invasive procedure that has a high negative predictive value and is therefore useful in ruling out obstructive coronary disease. Despite this in the UK where NICE recommendations apply challenges in adequate access to appropriate technology (cardiac-enabled CT) and human resources (sufficient numbers of appropriately trained radiographers and reporting staff) have been documented. ${ }^{5}$ In our local institution, the potential to increase inpatient CTCA availability was improved by the installation of an additional CT scanner with cardiac capability.

In January 2020, a care pathway was agreed between the cardiology, radiology and EDs in our facility to implement a strategy of CTCA 
as a first-line inpatient examination for selected patients with chest pain of low to moderate risk of significant coronary artery disease with a plan to prospectively evaluate the impact on length of stay and clinical outcomes including subsequent invasive angiography and revascularisation, and major adverse cardiac events at 30 days. From mid-March 2020, due to COVID-19 restrictions in our hospital and reconfiguration within the non-invasive diagnostic laboratory, treadmill exercise testing was not available as an alternative to CTCA and we continued to evaluate length of stay and clinical outcomes

\section{METHODS \\ Design}

Three cohorts that included all patients presenting to ED in St. James Hospital with chest pain and/or dyspnoea, who were initially assessed by the ED team and referred to the cardiology team were assessed. Cohort 1 was the baseline cohort prior to increased availability of CTCA, retrospectively collected. Cohort 2 was post the increased CTCA availability agreement, and cohort 3 after the national lockdown was announced in Ireland due to COVID-19. Interhospital transfers, as well as patients from the local catchment area who were brought by ambulance straight to the catheter lab, were excluded.

\section{Patients}

Diagnosis code within the Hospital Inpatient Enquiry dataset provided patient suitable for inclusion. This dataset is used throughout hospitals in the Ireland to record inpatient and outpatient statistics. The St. James Hospital Electronic Patient Record retrospectively provided chart information; patient clinical features, investigations and length of stay data. Referral to the cardiology service was determined on clinical suspicion by the emergency medicine physician that the presentation was due to a cardiac cause, taking into account presenting complaint, risk factor profile and preliminary biochemical and radiological investigations. Patients with a diagnosis of non-ST elevation myocardial infarction were included in this study.

\section{Definitions}

Family history in this study was defined as a first-degree male relative $<55$ years, or first-degree female relative $<65$ years with ischaemic cardiac disease. History of diabetes mellitus included both type 1 and type 2 disease. History of cerebrovascular/cardiovascular disease included patients with transient ischaemic attack, cerebrovascular accident and/or coronary artery disease. A history of coronary artery disease originated either from the medical history the patient provided, or from the hospital patient records. Blood pressure and heart rate readings are those documented at time of admission under the cardiology service. Weight is that documented during the admission by standard scales. Outpatient functional imaging recorded were stress-perfusion cardiac MRI, dobutamine stress echocardiography, single-photon emission CT. Outpatient anatomical imaging included CTCA and invasive coronary angiography. Total amount of CTCA described in table 1 includes the percentage of overall patients who underwent imaging. Revascularisation refers to usage of percutaneous coronary intervention or surgical correction (eg, coronary artery bypass graft). A negative troponin- $\mathrm{T}$ result is expressed as $<14 \mathrm{ng} / \mathrm{L}$ in our laboratory. Estimated glomerular filtration rate (eGFR) was calculated using the MDRD equation, expressed as $\mathrm{ml} / \mathrm{min} / 1.73 \mathrm{~m}^{2}$. An ischaemic ECG is defined as any morphological changes on ECG consistent with ischaemic-type abnormalities that had not been documented before in that patient. 'Time to CTCA' is the length between placement of the electronic request for CTCA and the time at which the CTCA began. CTCA was performed on a 128-slice multidetector Siemens CT, image assessment was by radiology consultants trained in their interpretation. Normal CTCA was considered a report that described no abnormal coronary findings. Major adverse cardiac events were defined as death or further myocardial infarction in succeeding 1-month postadmission. This was achieved by follow-up phone call. Predetermined CTCA protocol in our facility required a heart rate $<60$ beats per minute before CT performance in patients undergoing CTCA to assess for coronary artery disease. Nebivolol $10 \mathrm{mg}$ per oral was our chosen oral agent to achieve the required heart rate, with additional $5-10 \mathrm{mg}$ doses per oral as required. Intravenous metoprolol could be used as a short acting alternative to achieve optimal heart rate. A 18 gauge intravenous cannulation was required to administer CTCA contrast. Performance of CTCA was only available between working hours of Monday to Friday.

\section{Statistical analysis}

Statistical analysis was performed using SPSS (V.25). Unpaired two-tailed t-test was used for continuous variables significance. $\chi^{2}$ test was used for categorical data significance. Analysis of variance was used to test for difference in mean values among multiple groups. Statistical significance was taken to be $p \leq 0.05$. Results are expressed as the median for continuous variables, with IQRs included. Missing data are acknowledged and listed with the results. Poisson regression was used to test for significance when outcome variable was a count.

\section{Patient and public involvement statement}

The patients involved in this research were recruited retrospectively after their admission and discharge from the hospital. As a result they were not involved in study design.

\section{RESULTS}

From October 2019 to May 2020, 513 patients (35.3\% female) presented with chest pain or dyspnoea thought to be cardiac in origin and were referred to the cardiology service for in-patient assessment. Cohort $1(\mathrm{n}=179)$ from 14 October 2019 to 30 December 2019, cohort 2 
Health care delivery, economics and global health care

Table 1 CTCA cohort characteristics

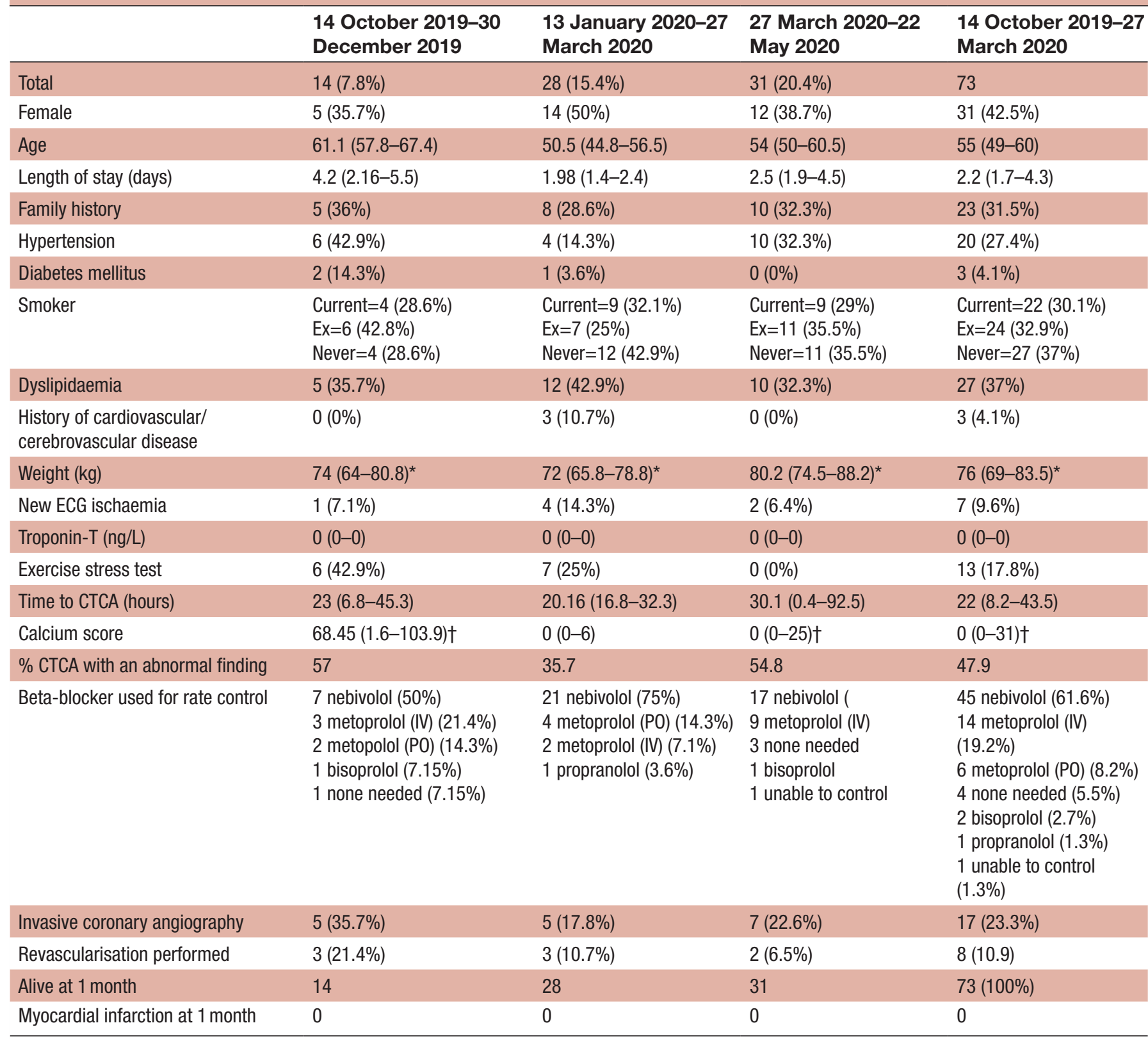

*Weight: not available=3 in cohort 1, 4 in cohort 2, 5 in cohort 3

†Calcium score: not available $=4$ in cohort 1, 4 in cohort 3 .

CTCA, CT coronary angiography.

$(\mathrm{n}=182)$ from 13 January 2020 to 27 March 2020, and cohort 3 ( $\mathrm{n}=153$ ) from 27 March 2020 to 22 May 2020. Demographics, cardiovascular risk factors and clinical features on presentation were recorded (see tables 2 and 3).

Differences were noted in baseline characteristics between cohort 1 and subsequent cohorts, with a higher prevalence of self-reported hypertension, family history of ischaemic heart disease, diabetes mellitus and current/ ex-smoking habit. The prevalence of new ECG ischaemia was also higher in between cohort 1 and $2(\mathrm{p}=0.001)$, and between cohort 1 and $3(p=0.000015))$. Larger rate of troponin rise on admission were noted in cohort 1
Table 2 Risk factor profile

Cohort 1, Cohort 2, Cohort 3, $\% \quad \%$

\begin{tabular}{lllr} 
& $\%$ & $\%$ & $\%$ \\
\hline Family history & 46.9 & 22.5 & 26.1 \\
Hypertension & 55.9 & 46.7 & 39.2 \\
Diabetes mellitus & 17.3 & 11 & 7.8 \\
$\begin{array}{l}\text { History of cardio/ } \\
\text { cerebrovascular disease }\end{array}$ & 41.3 & 36.8 & 32.7 \\
\begin{tabular}{l} 
Current/ex-smoker \\
\hline
\end{tabular} & 64.3 & 58.8 & 59.9 \\
\hline
\end{tabular}




\begin{tabular}{|c|c|c|c|}
\hline & $\begin{array}{l}14 \text { October } 2019-30 \\
\text { December } 2019\end{array}$ & $\begin{array}{l}13 \text { January 2020-27 } \\
\text { March } 2020\end{array}$ & $\begin{array}{l}27 \text { March 2020-22 May } \\
2020\end{array}$ \\
\hline Total & 179 & 182 & 153 \\
\hline Female & $59(33 \%)$ & $71(39.9 \%)$ & $51(33.3 \%)$ \\
\hline Presenting complaint & $\begin{array}{l}153 \text { chest pain }(85.5 \%) \\
26 \text { dyspnoea }(14.5 \%)\end{array}$ & $\begin{array}{l}151 \text { chest pain }(83 \%) \\
6 \text { dyspnoea }(3 \%) \\
25 \text { chest pain/dyspnoea }(14 \%)\end{array}$ & $\begin{array}{l}131 \text { chest pain }(85.6 \%) \\
8 \text { dyspnoea }(5.2 \%) \\
14 \text { chest pain/dyspnoea }(9.2 \%\end{array}$ \\
\hline Age & $62.6(55.7-71.8)$ & $59(50-70)$ & $59(50-70)$ \\
\hline Length of stay (days) & $2.66(0.96-4.92)$ & $2.16(1.2-5.1)$ & $1.71(1-3.3)$ \\
\hline Family history & $84(46.9 \%)$ & $41(22.5 \%)$ & $40(26.1 \%)$ \\
\hline Hypertension & $100(55.9 \%)$ & $85(46.7 \%)$ & $60(39.2 \%)$ \\
\hline Diabetes mellitus & $31(17.3 \%)$ & $20(11 \%)$ & $12(7.8 \%)$ \\
\hline Smoker & $\begin{array}{l}49 \text { current }(27.4 \%) \\
66 \text { ex }(36.9 \%) \\
64 \text { never }(35.7 \%)\end{array}$ & $\begin{array}{l}46 \text { current }(25.3 \%) \\
61 \text { ex }(33.5 \%) \\
75 \text { never }(41.2 \%)\end{array}$ & $\begin{array}{l}38 \text { Current }(25 \%) \\
53 \text { ex }(34.9 \%) \\
62 \text { never }(40.1 \%)\end{array}$ \\
\hline Dyslipidaemia & $94(52.5 \%)$ & $97(53.3 \%)$ & $71(46.4 \%)$ \\
\hline $\begin{array}{l}\text { History of cardiovascular/cerebrovascular } \\
\text { disease }\end{array}$ & $74(41.3 \%)$ & $67(36.8 \%)$ & $50(32.7 \%)$ \\
\hline Systolic blood pressure & $126(110-114)$ & $136(121-153)$ & $144(125-156)$ \\
\hline Diastolic blood pressure & $74(66-81.5)$ & $81(72-89)$ & $82(74-89)$ \\
\hline Heart rate & $70(64-79)$ & $76(66-86)$ & $72(65-84)$ \\
\hline Weight (kg) & $78(69.9-90.9)^{*}$ & $80(70-89.4)^{*}$ & $80.5(73.8-93.5)^{*}$ \\
\hline New ECG ischaemia & $63(35.2 \%)$ & $36(19.8 \%)$ & $22(14.3 \%)$ \\
\hline Troponin-T (ng/L) & $15(0-44)$ & $0(0-21.5)$ & $0(0-20)$ \\
\hline eGFR (ml/min/1.73m2) & 84 (67-99) & $90(75-107)$ & $89(72-103)$ \\
\hline CTCA amount & $14(7.8 \%)$ & $28(15.4 \%)$ & $31(20.3 \%)$ \\
\hline Exercise stress test & $43(24 \%)$ & $47(25.8 \%)$ & $0(0 \%)$ \\
\hline Invasive coronary angiography & $82(45.8 \%)$ & $71(39 \%)$ & $52(33.9 \%)$ \\
\hline Revascularisation performed & $53(29.6 \%)$ & $29(15.9 \%)$ & $25(16.3 \%)$ \\
\hline Death at 1 month & $6(3.4 \%)$ & $1(0.5 \%)$ & $2(1.3 \%)$ \\
\hline Myocardial infarction at 1 month & 0 & 1 & 1 \\
\hline Outpatient functional/anatomical imaging & $\begin{array}{l}\text { Total } 23(12.8 \%) \\
9 \text { invasive coronary angiogram (39\%) } \\
4 \text { stress perfusion cardiac MRI } \\
(17.4 \%) \\
4 \text { dobutamine stress } \\
\text { echocardiography }(17.4 \%) \\
3 \text { single-photo emission CT }(13.1 \%) \\
3 \text { CTCA }(13.1 \%)\end{array}$ & $\begin{array}{l}\text { Total } 28(15.4 \%) \\
10 \text { stress perfusion cardiac } \\
\text { magnetic resonance imaging } \\
(35.7 \%) \\
6 \text { Invasive coronary angiogram } \\
(21.4 \%) \\
5 \text { CTCA }(18 \%) \\
4 \text { single-photo emission CT (14\%) } \\
3 \text { dobutamine stress } \\
\text { echocardiography }(10.9 \%)\end{array}$ & $\begin{array}{l}\text { Total } 26(16.9 \%) \\
11 \text { CTCA }(42.3 \%) \\
9 \text { invasive coronary angiogram } \\
(34.6 \%) \\
4 \text { Stress perfusion cardiac } \\
\text { magnetic resonance imaging } \\
(15.4 \%) \\
1 \text { dobutamine stress } \\
\text { echocardiography }(3.85 \%) \\
1 \text { single-photo emission CT } \\
(3.85 \%)\end{array}$ \\
\hline
\end{tabular}

*Weight: not available $=36$ in cohort 1,39 in cohort 2, 50 in cohort 3.

CTCA, CT coronary angiography; eGFR, estimated glomerular filtration rate.

when compared with cohort $2(\mathrm{p}=0.0094)$, and cohort $3(\mathrm{p}=0.0044)$. Median eGFR in cohort 1 was lower than cohort $2(\mathrm{p}=0.002))$ and cohort $3(\mathrm{p}=0.018))$.

Use of CTCA increased from $7.8 \%$ overall use in cohort $1 \%$ to $15.4 \%$ in cohort 2 , and $20.4 \%$ in cohort $3(p=0.148)$ (see figure 1). Characteristics of patients undergoing CTCA are listed in table 3. Abnormal CTCA findings within the coronary arteries were documented in $57 \%, 35.7 \%$ and $54.8 \%$, respectively. The median length of stay in cohort 1 was 2.66 days, decreasing to 2.16 days in cohort $2(\mathrm{p}=0.53)$ and to 1.71 days in cohort $3(\mathrm{p}=0.014)$ (see figure 2). Overall length of stay for the patients undergoing CTCA decreased from a median of 4.2 days in cohort 1 to 1.98 days in cohort 2 , and 2.5 days 


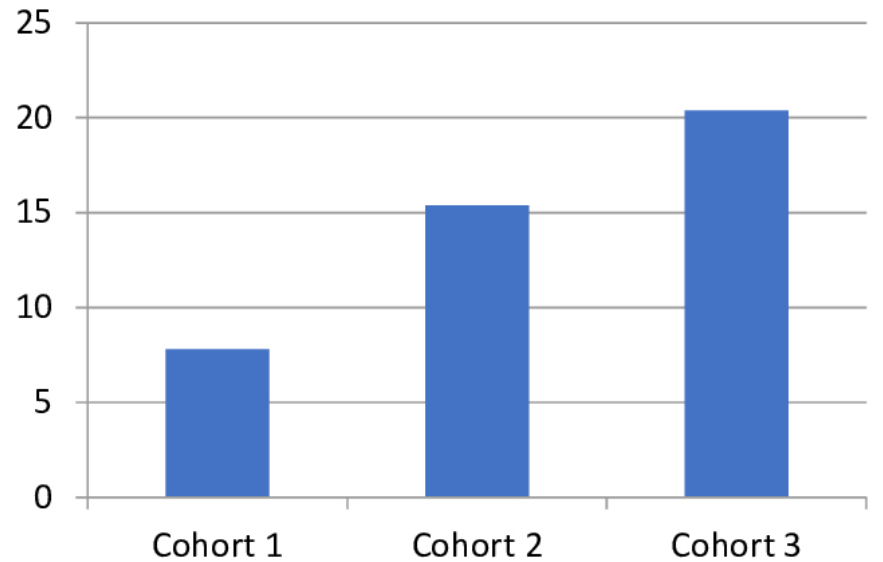

Figure 1 Number of CTCA (\% of performance In overall cohort). CTCA, CT coronary angiography.

in cohort $3(p=0.28)$ (figure 2$)$. Use of exercise stress testing ceased in cohort 3 , but had similar prevalence in cohorts 1 and 2.

Using poisson regression via a probability mass function, the time periods across cohorts $1(\mathrm{p}=0.028)$ and $3(\mathrm{p}=0.03)$, respectively, had a significant effect on the mean rate of CTCA. This significance was lost in cohort 2. Within multivariate regression analysis, a history of cerebrovascular/cardiovascular disease was significantly associated with CTCA use $(p=0.00097)$ in cohort 1. Age $(p=0.0017)$, hypertension $(p=0.001)$ and history of cerebrovascular/cardiovascular disease $(p=0.0015)$ were associated with CTCA use in cohort 2. Diabetes $(\mathrm{p}=0.037)$ and history of cerebrovascular/cardiovascular disease $(p=0.000246)$ were significantly associated with CTCA use in cohort 3. Time to CTCA reduced between cohort 1 and $2(p=0.6)$, but rose in cohort $3(p=0.135)$.

Invasive coronary angiography rate dropped from $45.8 \%$ to $39 \%$ in cohort $2(p=0.19)$, and to $34.2 \%$ in cohort $3(\mathrm{p}=0.0286)$. Revascularisation was required in $29.6 \%$ in cohort $1,15.9 \%$ in cohort $2(p=0.0019)$ and $16.3 \%$ in cohort $3(\mathrm{p}=0.00448)$ (see figure 3$)$. Daily rate of ED referral to cardiology increased from 2.32 to 2.46 and 2.73. Daily ST-elevation myocardial infarction code activation dropped from 1.29 to 1.14 and 1 , and daily

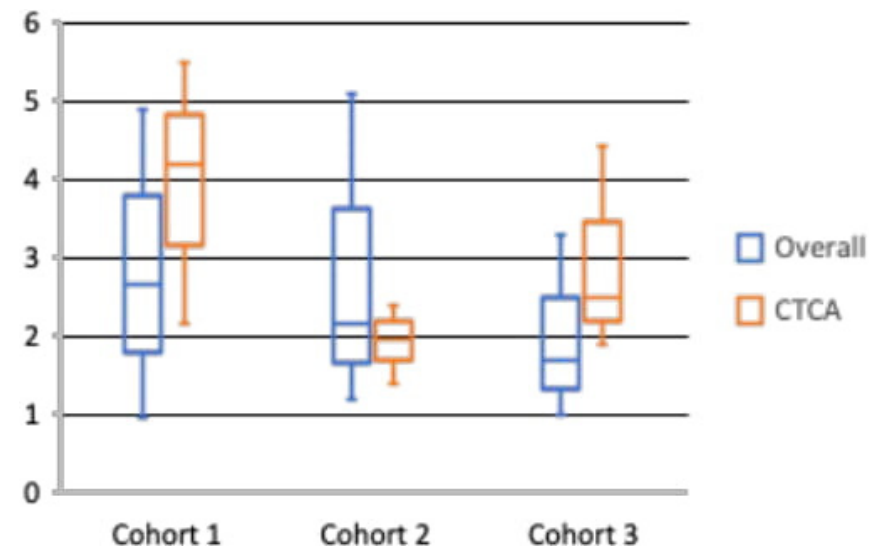

Figure 2 Overall/CTCA length of stay median/IQR (days). CTCA, CT coronary angiography.

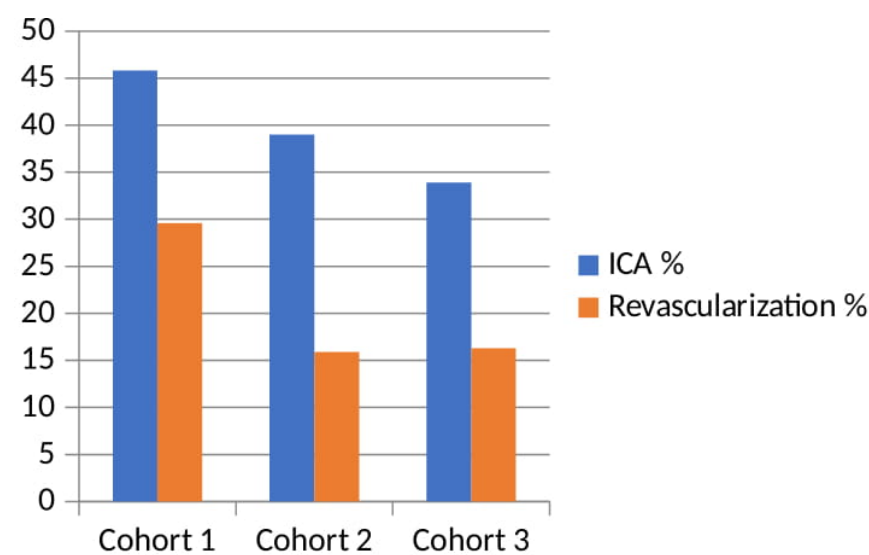

Figure 3 Invasive coronary angiography (ICA)/ revascularisation rates.

false rate of ST-elevation myocardial infarction activation increased from 0.039 to 0.068 then 0.14 . Rate of major adverse cardiac events remained low-rate of death was $3.4 \%, 0.5 \%$ and $1.3 \%$, respectively. Rate of non-fatal myocardial infarction at 30 days was $0 \%, 0.005 \%$ and $0.006 \%$, respectively.

\section{DISCUSSION}

Our findings demonstrate a decrease in length of stay with a switch to the use of CTCA rather than exercise testing for the investigation of acute chest pain. This was achieved with no significant increase in the rate of death, or non-fatal myocardial infarction at 30 days, and was possible throughout the COVID-19 pandemic when access to exercise testing was precluded locally due to infection control and staff restrictions. Before January 2020, CTCA in our facility had been used as outpatient test primarily for a low-risk patient cohort, with inpatient imaging limited to very selected patients, frequently not for coronary artery disease. With the challenges of COVID-19 all exercise stress testing was immediately discontinued and a replaced with CTCA as the main noninvasive diagnostic test for this cohort.

Over an 8-month period, our facility performed 73 inpatient CTCA. No fatalities or acute myocardial infarction at 1 month were reported. The time to CTCA reduced between cohort 1 and 2 (23 vs 20.1 hours $(p=0.6)$ ) but rose to 30.1 hours median in cohort $3(\mathrm{p}=0.135)$. When the COVID-19 pandemic occurred the provision of exercise stress testing ceased, leading to an increased use of CTCA for diagnostics, which is felt to contribute towards this finding. Throughout cohort 3 CT imaging facilities were split, with one CT scanner solely used for patients potentially positive with SARS-CoV-2. The significant reduction in length of stay between cohorts 1 and 2 in the CTCA subgroup is considered essentially a pre-COVID period finding. $19.2 \%(n=14)$ required intravenous betablockade to adequately control heart rate before CTCA. Initially, our facility found some operational difficulties in providing inpatient CTCA in scheduling a trained radiographer to facilitate imaging, and ensuring a physician 
be present in a timely fashion when required. Need for early oral beta-blockade and access with 18 gauge venous cannulation became more widely known as our front line staff gained familiarity with CTCA. The improvements seen across these elements remains a long-term priority of our facility. Overall length of stay for the patients undergoing CTCA decreased from a median of 4.2 days in cohort 1 to 1.9 days in cohort 2 , and 2.5 days in cohort 3.

It is worth noting that almost all patients who had a normal CTCA were discharged the same day, and so a 7-day provision is likely to have an even greater impact on length of stay. The agreement made in January 2020 between the cardiology, radiology and EDs precluded CTCA from being provided out of usual working hours. This study recruited patients admitted both on weekdays and weekend. As a result, the median length of stay results in this review are lengthened, with a saturation of requests preventing provision of a same-day service. Further improvements in length of stay are feasible if CTCA provision increases. The COVID-19 pandemic impacted multiple facets of the emergency, diagnostic imaging and cardiac services. Not only did the pandemic directly impact the number of patients attending ED, it also complicated access to diagnostics due to infection control protocols. A reduction in the rates of invasive coronary angiography and revascularisation was noted, but this may pertain to the baseline characteristics of the patient population in cohort 1 who were older with a higher proportion of ECG and troponin abnormalities. In non-pandemic circumstances, these patients would not often be deemed appropriately investigated by CTCA, but patients with ECG and troponin abnormalities were included in our CTCA cohort during the pandemic because of the known increased prevalence of these abnormalities with COVID-19. In such cases, the CTCA was a useful test to exclude significant coronary disease when there was clinical suspicion also of myocarditis or pericarditis due to SARS-CoV-2.

An increase in daily rate of referral to the cardiology service over the study period was noted, with a slight trend of a lower rate of daily ST-elevation myocardial infarction presentations. Across cohort 1, our facility had 102 emergency activations for community STEMI (99 confirmed on discharge by invasive coronary angiography), cohort 2, 89 activations (84 confirmed) and cohort 3, 64 activations (56 confirmed). The cohorts in this study are primarily haemodynamically stable patients from the local catchment area, although a minority became unstable while under review in ED, necessitating emergent invasive coronary angiography. Much of the recent work on the use of CTCA has been centred on patients presenting to the ED with acute chest pain. The current model of admitting patients to the hospital to 'rule out acute coronary syndrome' with serial biomarkers and functional assessment is both time and cost inefficient and leads to overcrowding in hospitals. ${ }^{4}$ Randomised trials have shown that CTCA in the ED setting for low to intermediate-risk chest pain reduces length of stay, initial cost in the ED, and time to discharge when compared with the current standard of care with equivalent safety and accuracy. ${ }^{6}$ CTCA has a high negative predictive value of up to $99 \%,{ }^{7}$ with its primary role to rule out coronary artery disease. ${ }^{8}$

The implementation of the 2016 NICE guidelines for CTCA for stable chest pain has put significant strain on resources and infrastructure both in terms of personnel and equipment due to the vastly increased numbers of patients needing CT scans. ${ }^{5}$ As CTCA is a relatively new technology, some older CT scanners do not have the hardware necessary to perform these scans and most technicians have not been trained to properly gate their CT scanners for use in CTCA; in fact there are currently only 15 radiologists and 14 cardiologists with the expertise to report CTCAs in the Irish public health system. ${ }^{9}$ Further there are 23 CT scanners in the Irish public system currently capable of performing CTCA and a further 22 scanners with capacity following a software upgrade. ${ }^{9}$

\section{LIMITATIONS}

The authors appreciate the limitations in this study, containing retrospective data from a single centre. Data from a single centre are subject to convenience sampling, and retrospective data are associated with confounding which may distort the true relationships between the variables analysed. Performance of this study across multiple centres would have helped mitigate bias. A longer period of follow-up would ensure adequate detection of major adverse outcomes.

\section{CONCLUSION}

Our study demonstrated an increase in inpatient CTCA provision. The doubling of proportion of patients investigated by CTCA from $7.8 \%$ to $15.4 \%$ was associated with a reduction in length of stay from 4.2 days to 1.98 days. The improved efficiency in processing these intermediate rather than high-risk patients was maintained during the COVID-19 pandemic, with a continued lower length of stay. A corresponding reduction in the rates of invasive coronary angiography and revascularisation was seen, without an increase in 30-day major adverse cardiac events.

Contributors All authors made a significant contribution to the design of this study, analysis of data and drafting of the final manuscript. All coauthors have approved the final draft. CD, as head of the cardiology department in St. James Hospital, acts as overall content guarantor.

Funding The authors have not declared a specific grant for this research from any funding agency in the public, commercial or not-for-profit sectors.

Competing interests None declared.

Patient consent for publication Not required.

Ethics approval This study was approved by the research and ethics committee in St. James Hospital, Dublin. (Ref. 6280).

Provenance and peer review Not commissioned; externally peer reviewed. 
Data availability statement All data relevant to the study are included in the article or uploaded as online supplemental information. Deidentified participant data are stored on a secure encrypted hard drive in St. James Hospital as agreed with by the research and ethics committe. It has been pseudonymised and is registered with the data protection office and research and innovation office in St. James Hospital.

Open access This is an open access article distributed in accordance with the Creative Commons Attribution Non Commercial (CC BY-NC 4.0) license, which permits others to distribute, remix, adapt, build upon this work non-commercially, and license their derivative works on different terms, provided the original work is properly cited, appropriate credit is given, any changes made indicated, and the use is non-commercial. See: http://creativecommons.org/licenses/by-nc/4.0/.

ORCID iDs

Michael Cronin http://orcid.org/0000-0003-1088-1668

Rajesh Kumar http://orcid.org/0000-0002-8002-1551

\section{REFERENCES}

1 Fothergill NJ, Hunt MT, Touquet R. Audit of patients with chest pain presenting to an accident and emergency department over a 6-month period. Arch Emerg Med 1993;10:155-60.
2 Kohn MA, Kwan E, Gupta M, et al. Prevalence of acute myocardial infarction and other serious diagnoses in patients presenting to an urban emergency department with chest pain. J Emerg Med 2005;29:383-90.

3 SCOT-HEART investigators. Ct coronary angiography in patients with suspected angina due to coronary heart disease (SCOT-HEART): an open-label, parallel-group, multicentre trial. Lancet 2015;385:2383-91.

4 Alfakih K, Greenwood JP, Plein S. The 2016 update to NICE CG95 guideline for the -investigation of new onset stable chest pain: more -innovation, but at a cost? Clin Med 2017;17:209-11.

5 Dreisbach JG, Nicol ED, Roobottom CA, et al. Challenges in delivering computed tomography coronary angiography as the first-line test for stable chest pain. Heart 2018;104:921-7.

6 Goyal N, Stillman A. Coronary CT angiography in acute chest pain. F1000Res 2017;6:1125-25.

7 Miller JM, Rochitte CE, Dewey M, et al. Diagnostic performance of coronary angiography by 64-row CT. N Engl J Med 2008;359:2324-36.

8 Wallis A, Manghat N, Hamilton M. The role of coronary CT in the assessment and diagnosis of patients with chest pain. Clin Med 2012;12:222-9.

9 Giblin G, McAdam B. 55 Provision of cardiac CT angiography services within the irish public health service. Heart 2019;105:A43. 